\title{
Single-Centre Retrospective Study Using Propensity Score Matching Comparing Left Versus Right Internal Jugular Vein Access for Transjugular Intrahepatic Portosystemic Shunt (TIPS) Creation
}

\author{
Zhenkang Qiu ${ }^{1}$ Wenliang Zhu ${ }^{1} \cdot$ Huzheng Yan ${ }^{1,2}$ - Guobao Wang ${ }^{3} \cdot$

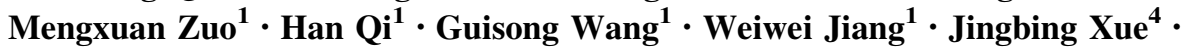 \\ Fujun Zhang $^{1} \cdot$ Fei Gao ${ }^{1}$
}

Received: 17 August 2021 / Accepted: 5 November 2021 / Published online: 1 January 2022

(C) The Author(s) 2021

\begin{abstract}
Purpose To compare the safety and efficacy of left versus right internal jugular vein access for portal vein puncture during transjugular intrahepatic portosystemic shunt (TIPS) creation in patients with a small liver and short vertical puncture distance.

Materials and Methods The vertical distance from the hepatic vein orifice to the puncture point of the portal vein was measured by CT and DSA. A distance $\leq 30 \mathrm{~mm}$ is defined as a short vertical puncture distance. After 1:1 propensity score matching (PSM), 29 patients of left internal jugular vein-TIPS (LIJ-TIPS) and 29 patients of right internal jugular vein-TIPS (RIJ-TIPS) were included. The number of needle punctures, fluoroscopy time, and
\end{abstract}

Zhenkang Qiu and Wenliang Zhu are contributed equally to this work.

Fujun Zhang

zhangfj@sysucc.org.cn

$\square$ Fei Gao

gaof@sysucc.org.cn

1 Department of Minimally Invasive \& Interventional Radiology, Sun Yat-Sen University Cancer Center and Sun Yat-Sen University State Key Laboratory of Oncology in South China, Collaborative Innovation Center for Cancer Medicine, 651 Dongfeng East Road, Guangdong 510060, Guangdong Province, China

2 Department of Interventional Radiology, The Third Affiliated Hospital of Sun Yat-Sen University, Guangzhou, China

3 Department of Endoscopy, Collaborative Innovation Center for Cancer Medicine, Sun Yat-Sen University Cancer Center and Sun Yat-Sen University State Key Laboratory of Oncology in South China, Guangzhou, Guangdong, China

4 Department of Imaging Sciences, University of Rochester Medical Center, Rochester, NY, USA radiation dose during the puncture process were statistically analyzed.

Results There was no significant difference in the average vertical puncture distances on CT or DSA between LIJTIPS and RIJ-TIPS $(19.10 \pm 0.60 \mathrm{~mm}$ vs. $19.30 \pm$ $0.60 \mathrm{~mm}, \quad P=0.840 ; \quad 22.02 \pm 0.69 \mathrm{~mm} \quad$ vs. $\quad 22.23 \pm$ $0.64 \mathrm{~mm}, P=0.822$, respectively). The average number of needle punctures, fluoroscopy time, and radiation dose in LIJ-TIPS were significantly lower than those in RIJ-TIPS $(2.07 \pm 0.20$ vs. $4.10 \pm 0.24, P<0.001 ; 78.45 \pm 12.80 \mathrm{~s}$ vs. $201.16 \pm 23.71 \mathrm{~s}, P<0.001 ; 31.55 \pm 7.04 \mathrm{mGy} v s$. $136.69 \pm 16.38 \mathrm{mGy}, P<0.001$, respectively). Within three punctures, the technical success rate in LIJ-TIPS was significantly higher than that in RIJ-TIPS (86.2 vs. 27.6\%, $P<0.001)$. The incidence of hemoperitoneum in LIJ-TIPS was significantly lower than that in RIJ-TIPS (0\% vs. $13.8 \%, P=0.038$ ).

Conclusion The left internal jugular vein could be used as primary access for TIPS creation in patients with a small liver and short vertical puncture distance.

Keywords TIPS - Left internal jugular vein access · Liver cirrhosis

\section{Introduction}

Transjugular intrahepatic portosystemic shunt (TIPS) has resulted in significant progress in the management of portal hypertension-related complications in patients with cirrhosis [1-4]. More than $90 \%$ of TIPS procedures in experienced centers can be performed via the right internal jugular vein (RIJ), a preferred access for the procedure 
$[5,6]$. The main characteristic of severe cirrhosis is a reduction in liver volume, which shortens the distance between the hepatic vein and the portal vein $[7,8]$. In clinical practice, the left internal jugular vein (LIJ) can be used for a second TIPS attempt when the RIJ is not available for access [9, 10]. However, limited data comparing RIJ versus LIJ access for TIPS creation exist. This study compared LIJ versus RIJ access for TIPS creation.

\section{Materials and Methods}

This single-center retrospective study was performed according to the Declaration of Helsinki (2013) of the World Medical Association and approved by the
Institutional Review Board of our center, who waived the need for informed patient consent. The vertical puncture distance on CT was converted with the distance of vertical slices $(0.5 \mathrm{~cm}$ thick) from the hepatic vein orifice (Point A) to the puncture point of the portal vein (Point B) on preoperative CT. The vertical puncture distance on digital subtraction angiography (DSA) images was confirmed and measured directly with the computer's Picture Archiving and Communication Systems (PACS). A distance $\leq 30 \mathrm{~mm}$ is defined as a short vertical puncture distance. Patients were divided into the LIJ-TIPS group or the RIJ-TIPS group according to TIPS access; ultimately, a total of 29 patients were included in each group (Fig. 1).

All TIPS procedures were performed with the same X-ray angiography system and exposure mode (Philips

Patients underwent TIPS between March 2018 to December $2020(n=246)$

Inclusion criteria:

(i) cirrhosis with portal hypertension-related symptoms, including variceal bleeding and refractory ascites;

(ii) age $18-85$ years and receipt of TIPS treatment;

(iii) liver cirrhosis with short vertical puncture distance (Point A to Point $\mathrm{B}$ on $\mathrm{CT} \leq 30 \mathrm{~mm}$ ).

Excluded $(n=154)$

-with transhepatic approach $(n=19)$

-with transsplenic approach $(\mathrm{n}=5)$;

-previous TIPS placement $(n=5)$;

-TIPS technical failure $(n=2)$;

-lack of baseline data $(\mathbf{n}=19)$;

-lost follow-up $(\mathrm{n}=11)$;

-the vertical distance from Point A to Point B on CT $>30 \mathrm{~mm}(\mathrm{n}=93)$.

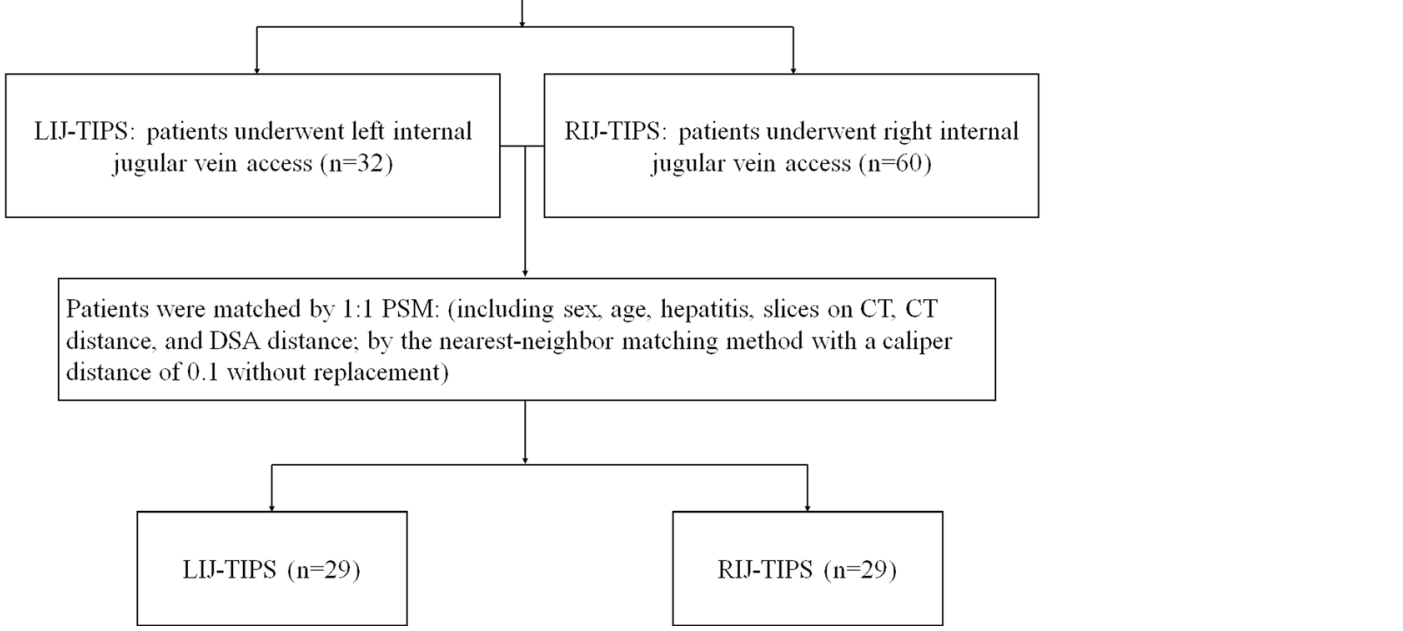

Fig. 1 Patient flow diagram. The inclusion criteria were as follows: (i) cirrhosis with portal hypertension-related symptoms, including variceal bleeding and refractory ascites; (ii) age 18-85 years and receipt of TIPS treatment; (iii) liver cirrhosis with short vertical puncture distance (Point A to Point B on CT $\leq 30 \mathrm{~mm}$ ). Patients with transhepatic approach $(n=19)$; with transsplenic approach $(n=5)$; previous TIPS placement $(n=5)$; TIPS technical failure because of portal vein occlusion and cavernous degeneration $(n=2)$; lack of baseline data $(n=19)$; lost follow-up $(n=11)$; and the vertical distance from Point A to Point B on CT $>30 \mathrm{~mm}(n=93)$ were excluded from the study. Note: The vertical distance from Point A to Point $B$ is the distance of vertical slices $(0.5 \mathrm{~cm}$ thick $)$ from the hepatic vein orifice to the puncture point of the portal vein on preoperative CT. LIJ access was used after a failed TIPS attempt from the RIJ access $(n=10)$. LIJ was chosen as first-line access upfront because of the short vertical puncture distance $(n=19)$. TIPS, transjugular intrahepatic portosystemic shunt; LIJ-TIPS, left internal jugular vein access; RIJ-TIPS, right internal jugular vein access; PSM, propensity score matching 
Fig. 2 Entrance of the stiffening cannula into the middle hepatic vein through the left internal jugular vein. a A 10 -Fr sheath is straightening the superior vena cava. b The stiffening cannula enters into the superior vena cava. $\mathbf{c}$ The stiffening cannula is passing through the right atrium. d Middle hepatic venography

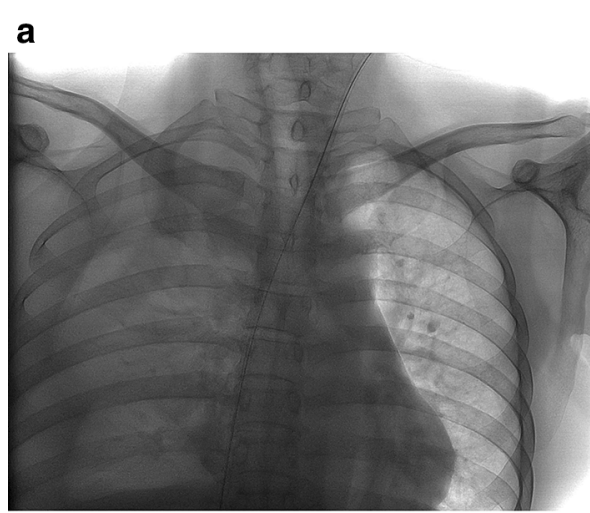

b

C
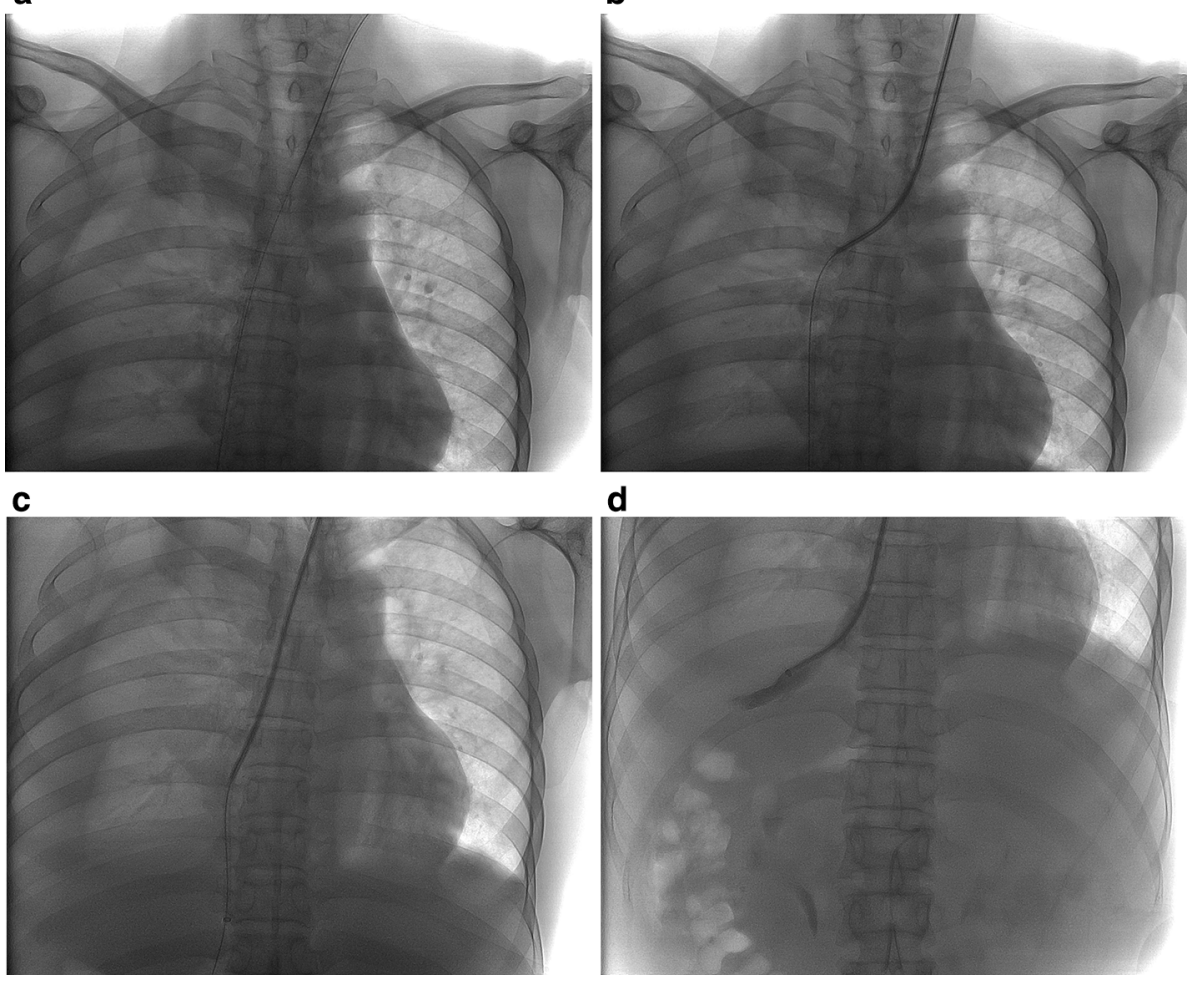

d

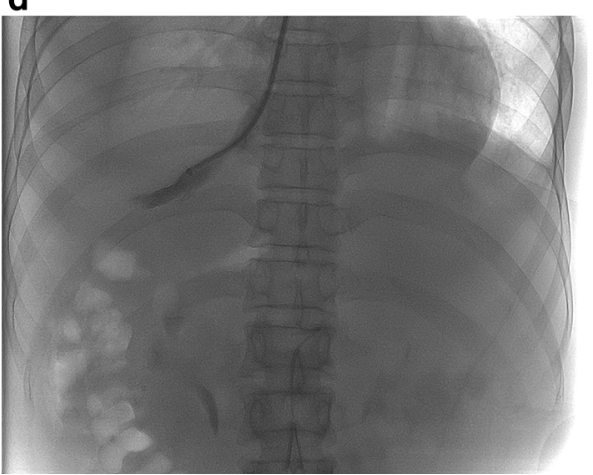

a

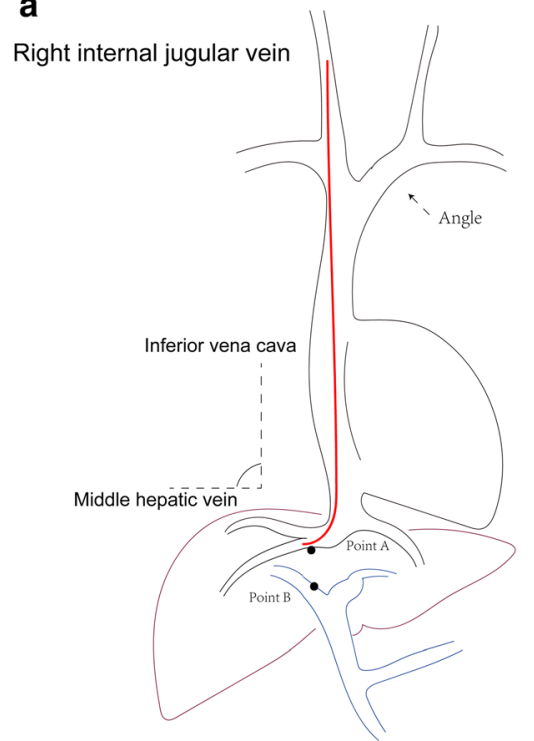

b

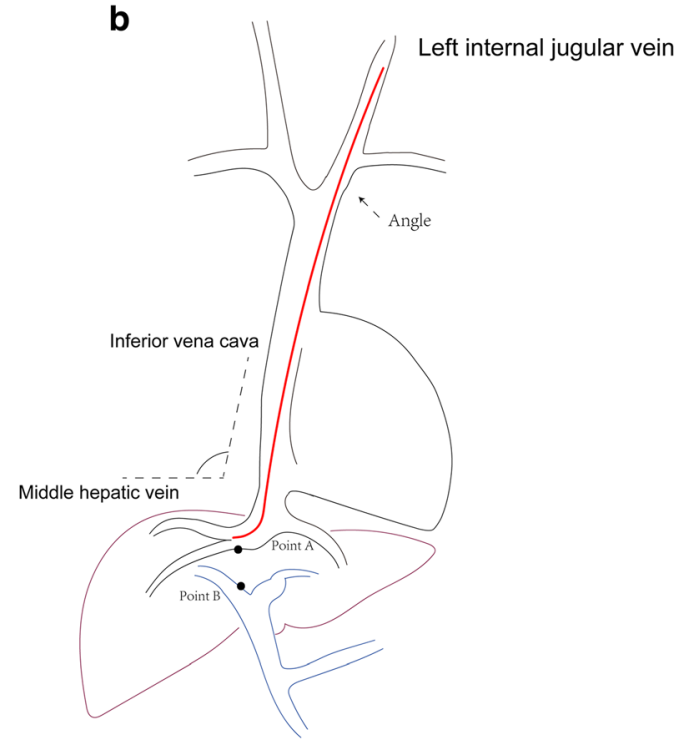

Fig. 3 Schematic diagram of RIJ-TIPS and LIJ-TIPS. a TIPS with right internal jugular vein access (RIJ-TIPS). b TIPS with left internal jugular vein access (LIJ-TIPS). Point A, hepatic vein orifice; Point $\mathrm{B}$, puncture point of the portal vein; TIPS, transjugular intrahepatic portosystemic shunt
AlluraXper FD20, Philips, Amsterdam, the Netherlands; Abdomen Frontal: 3 fps, Fluoroscopy: Normal level; Supplemental Fig. 1). LIJ was chosen as first-line access upfront or after a failed TIPS attempt from the RIJ access. A 10-Fr sheath (RUPS-100, Cook, Indiana, USA) was cannulated into the inferior vena cava. A 14-gage Stiffening Cannula (RUPS-100, Cook, Indiana, USA) was introduced into the middle hepatic vein and confirmed via hepatic venography, as shown in Fig. 2. A schematic diagram is shown in Fig. 3. Portal vein puncture was guided with indirect portal vein angiography and performed via the celiac trunk or superior mesenteric artery. The needle punctures, site of portal vein puncture, fluoroscopy time (s), and radiation dose (mGy) were recorded from middle hepatic venography to portal vein puncture success. Then, a balloon angioplasty catheter was inserted and deployed, and covered stents (W.L. Gore \& Associates, Flagstaff, AZ, USA) measuring $8 \mathrm{~mm}$ in diameter and 50 
Fig. 4 A 42-year-old male patient suffering from refractory ascites received a transjugular intrahepatic portosystemic shunt (TIPS) with left internal jugular vein access. a An

anteroposterior 3D image shows the short vertical distance between the hepatic vein and the portal vein. b Portography after the puncture. c Portography after the TIPS creation. d The short vertical puncture distance $(15.44 \mathrm{~mm})$ from Point A to Point B was measured directly with the computer's

Picture Archiving and Communication Systems (PACS). Note: The 3D image was made by a $3 \mathrm{D}$ visualization planning system (Hokai

Company, Zhuhai, China), which is only used to show the position of the hepatic vein and the portal vein and is not used to guide the puncture a

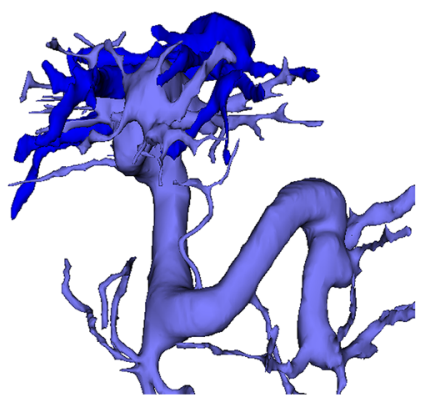

C

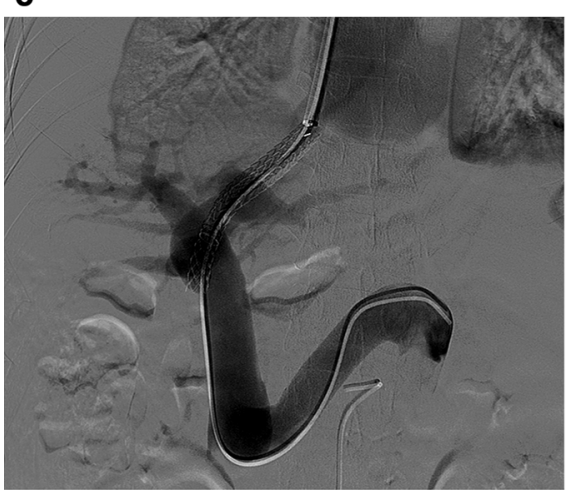

b

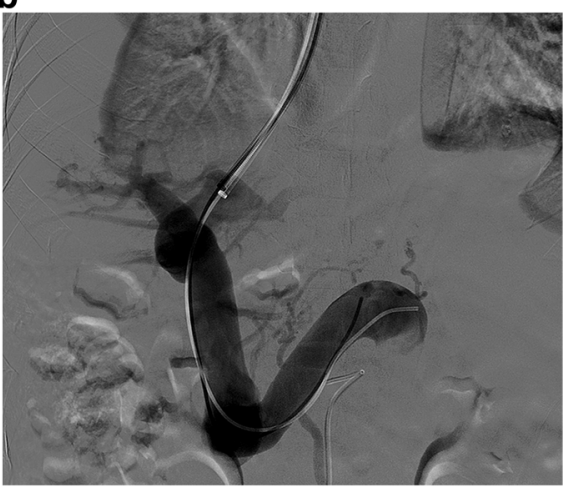

d

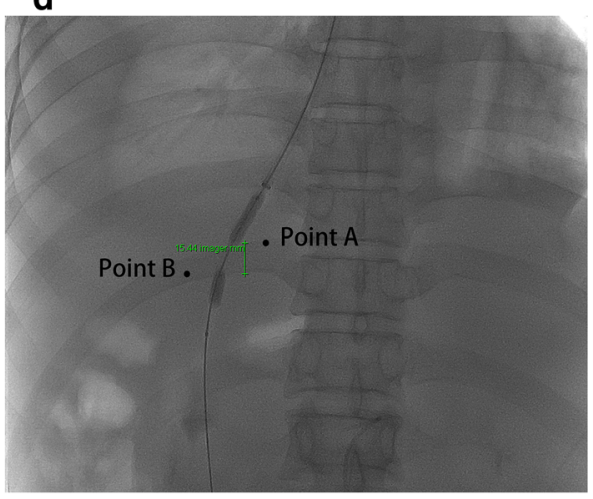

or $60 \mathrm{~mm}$ in length were placed. An example is illustrated in Fig. 4. The portosystemic pressure gradient (PSG) was measured before and after shunt creation. Six operators in our center performed the TIPS procedure with more than five years of experience (Supplemental Table 2). Bedside abdominal ultrasonography was performed to observe whether there was hemoperitoneum. Patients were followed up for 3 months after discharge. The follow-up protocol included assessment of recurrent bleeding, ascitis remission, puncture-related complications, hepatic encephalopathy (HE), routine blood tests, biochemistry, coagulation, color Doppler ultrasound, and enhanced CT of the upper abdomen to check stent patency.

Student's $t$-test was used to compare continuous variables, and categorical variables were compared using the Pearson $\chi^{2}$ test. The baseline patient data of the two groups (Supplemental Table 1) were matched with 1:1 propensity score matching (PSM). SPSS Statistics 26.0 (IBM, Armonk, NY) and R software package 3.5.0 (R Foundation for Statistical Computing, Vienna, Austria) were used for statistical analyses. Statistical tests were 2-tailed, and a $P$ value $\leq 0.05$ was considered to indicate statistical significance.

\section{Results}

The difference in the average vertical puncture distances on CT or DSA between LIJ-TIPS and RIJ-TIPS was not significant $(19.10 \pm 0.60 \mathrm{~mm} \quad$ vs. $19.30 \pm 0.60 \mathrm{~mm}$, $P=0.840 ; \quad 22.02 \pm 0.69 \mathrm{~mm} \quad$ vs. $22.23 \pm 0.64 \mathrm{~mm}$, $P=0.822$, respectively). There was no significant difference in the baseline characteristics between the two groups after PSM (Table 1).

The average number of needle punctures, fluoroscopy time, and radiation dose in LIJ-TIPS were significantly lower than those in RIJ-TIPS $(2.07 \pm 0.20$ vs. $4.10 \pm 0.24, \quad P<0.001 ; \quad 78.45 \pm 12.80 \mathrm{~s} \quad v s$. $201.16 \pm 23.71 \mathrm{~s}, \quad P<0.001 ; \quad 31.55 \pm 7.04 \mathrm{mGy} \quad v s$. $136.69 \pm 16.38 \mathrm{mGy}, \quad P<0.001$, respectively). Within three punctures, the technical success rate in LIJ-TIPS was significantly higher than that in RIJ-TIPS $(86.2 \%$ vs. $27.6 \%, P<0.001)$. There was no significant difference in the mean PSG reduction between LIJ-TIPS and RIJ-TIPS $(14.23 \pm 1.23 \mathrm{mmHg} \quad$ vs. $\quad 13.51 \pm 0.91 \mathrm{mmHg}$, $P=0.637$ ). During the 3 -month follow-up period, a $100 \%$ bleeding control rate was achieved in all of the patients. 
Table 1 Baseline patient characteristics after propensity score matching

\begin{tabular}{|c|c|c|c|c|}
\hline Characteristics & All $(n=58)$ & LIJ-TIPS $(n=29)$ & RIJ-TIPS $(n=29)$ & $P$-value \\
\hline Sex & & & & 1.000 \\
\hline Male & $52(89.7 \%)$ & $26(89.7 \%)$ & $26(89.7 \%)$ & \\
\hline Female & $6(10.3 \%)$ & $3(10.3 \%)$ & $3(10.3 \%)$ & \\
\hline Median age (range), years & $56.3[30.0 ; 80.0]$ & $56.6[30.0 ; 80.0]$ & $55.0[39.0 ; 80.0]$ & 0.865 \\
\hline Hepatitis B & & & & 0.277 \\
\hline Yes & $49(88.0 \%)$ & $26(89.7 \%)$ & $23(79.3 \%)$ & \\
\hline No & $9(12.0 \%)$ & $3(10.3 \%)$ & $6(20.7 \%)$ & \\
\hline Child-Pugh class & & & & 0.961 \\
\hline A & $23(39.7 \%)$ & $12(41.4 \%)$ & $11(37.9 \%)$ & \\
\hline B & $27(46.6 \%)$ & $13(44.8 \%)$ & $14(48.3 \%)$ & \\
\hline $\mathrm{C}$ & $8(13.8 \%)$ & $4(13.8 \%)$ & $4(13.8 \%)$ & \\
\hline Clinical symptoms & & & & 0.638 \\
\hline Variceal bleeding & $26(44.8 \%)$ & $14(48.3 \%)$ & $12(41.4 \%)$ & \\
\hline Refractory ascites & $19(32.8 \%)$ & $10(34.5 \%)$ & $9(31.0 \%)$ & \\
\hline Variceal bleeding + refractory ascites & $13(22.4 \%)$ & $5(17.2 \%)$ & $8(27.6 \%)$ & \\
\hline Slices on $\mathrm{CT}$ & & & & 0.956 \\
\hline 3 & $17(29.3 \%)$ & $9(31.0 \%)$ & $8(27.6 \%)$ & \\
\hline 4 & $33(56.9 \%)$ & $16(55.2 \%)$ & $17(58.6 \%)$ & \\
\hline 5 & $8(13.8 \%)$ & $4(13.8 \%)$ & $4(13.8 \%)$ & \\
\hline Vertical puncture distance on $\mathrm{CT}, \mathrm{mm}^{\#}$ & $19.50 \pm 0.50$ & $19.10 \pm 0.60$ & $19.30 \pm 0.60$ & 0.840 \\
\hline Vertical puncture distance on DSA, mm ${ }^{\#}$ & $22.00 \pm 0.58$ & $22.02 \pm 0.69$ & $22.23 \pm 0.64$ & 0.822 \\
\hline
\end{tabular}

Unless otherwise indicated, data are the number of patients, with percentages in parentheses; ${ }^{\#}$ means \pm standard deviation; slices on CT: the number of vertical slices $(0.5 \mathrm{~cm}$ thick) from the hepatic vein orifice to the puncture point of the portal vein on preoperative CT images. CT, computed tomography. A $P$-value $\leq 0.05$ was considered to indicate statistical significance

The remission rate of ascites was $73.3 \%(11 / 15)$ in LIJTIPS and $70.6 \%(12 / 17)$ in RIJ-TIPS $(P=0.863)$. (Table 2).

The incidence of hemoperitoneum in LIJ-TIPS was significantly lower than that in RIJ-TIPS (0\% vs. $13.8 \%$, $P=0.038$ ). In RIJ-TIPS, three patients had minor hepatic subcapsular hematoma and recovered after conservative treatment. One patient underwent hepatic arteriography and effective embolization due to severe intra-abdominal bleeding with a $22 \mathrm{~g} / \mathrm{L}$ drop in hemoglobin within four hours. These patients required an average of up to 5.75 punctures to achieve a successful TIPS. Three patients of LIJ-TIPS and two patients of RIJ-TIPS developed mild/moderate HE, but these symptoms improved through medical treatment. (Table 2).

\section{Discussion}

The LIJ can be a substitute access portal for TIPS, but limited data on its usefulness exist $[9,10]$. This singlecenter retrospective study compared RIJ versus LIJ access for TIPS creation. The LIJ was used in this study as a firstline approach or after failed RIJ access. Average vertical puncture distances of less than $25 \mathrm{~mm}$ were achieved in this study. The average needle puncture, fluoroscopy time, radiation dose of $\mathrm{X}$-ray, and hemoperitoneum risk during puncture can be reduced through LIJ access. Therefore, an LIJ-TIPS approach may be more suitable for such patients.

The relative spatial positions of the hepatic and portal veins can be changed by severe shrinkage in a cirrhotic liver $[7,8]$. Based on the findings of this study, a schematic diagram of LIJ-TIPS and RIJ-TIPS was made to show the different details of the two approaches. The angle between 
Table 2 Procedure details and outcomes

\begin{tabular}{|c|c|c|c|}
\hline Characteristics & $\begin{array}{l}\text { LIJ-TIPS } \\
(n=29)\end{array}$ & RIJ-TIPS $(n=29)$ & $P$-value \\
\hline Needle punctures \# & $2.07 \pm 0.20$ & $4.10 \pm 0.24$ & $<0.001 *$ \\
\hline$\leq 3, \%$ & $25(86.2 \%)$ & $8(27.6 \%)$ & $<0.001 *$ \\
\hline$>3, \%$ & $4(13.8 \%)$ & $21(72.4 \%)$ & \\
\hline Fluoroscopy time of puncture, second \# & $78.45 \pm 12.80$ & $201.16 \pm 23.71$ & $<0.001 *$ \\
\hline Radiation dose of puncture, $\mathrm{mGy}{ }^{\#}$ & $31.55 \pm 7.04$ & $136.69 \pm 16.38$ & $<0.001 *$ \\
\hline Point B & & & 0.525 \\
\hline Left branch of portal vein & $16(55.2 \%)$ & $13(44.8 \%)$ & \\
\hline Right branch of portal vein & $7(24.1 \%)$ & $11(37.9 \%)$ & \\
\hline Bifurcation of portal vein & $6(20.7 \%)$ & $5(17.2 \%)$ & \\
\hline \multicolumn{4}{|l|}{ PSG, mmHg ${ }^{\#}$} \\
\hline Pre-TIPS & $25.80 \pm 1.28$ & $26.45 \pm 1.32$ & 0.725 \\
\hline Post-TIPS & $11.56 \pm 0.91$ & $12.94 \pm 0.92$ & 0.293 \\
\hline Reduction & $14.23 \pm 1.23$ & $13.51 \pm 0.91$ & 0.637 \\
\hline \multicolumn{4}{|l|}{ Symptom control } \\
\hline No rebleeding & $19(100 \%)$ & $20(100 \%)$ & \\
\hline Ascites remission & $11 / 15(73.3 \%)$ & $12 / 17(70.6 \%)$ & 0.863 \\
\hline Hemoperitoneum & & & $0.038 *$ \\
\hline Minor & $3(10.3 \%)$ & $0(0 \%)$ & \\
\hline Severe & $1(3.4 \%)$ & $0(0 \%)$ & \\
\hline Hepatic encephalopathy & & & 0.640 \\
\hline Mild & $2(6.9 \%)$ & $1(3.4 \%)$ & \\
\hline Moderate & $1(3.4 \%)$ & $1(3.4 \%)$ & \\
\hline
\end{tabular}

Unless otherwise indicated, data are the number of patients, with percentages in parentheses; \# means \pm standard deviation; Point B, puncture point of the portal vein; TIPS, transjugular intrahepatic portosystemic shunt; PSG, portosystemic pressure gradient. *A $P$-value $\leq 0.05$ was considered to indicate statistical significance

the inferior vena cava and the middle hepatic vein is larger in LIJ-TIPS, which may be the reason why puncture is more effective [8]. Of note, care should be taken when the guidewire or guide passes through the heart area because of the increased length of the path [9]. The large venous structures of the mediastinum can be stretched when the stiffening cannula of the RUPS-100 passes through the two venous angles (the angle between the LIJ and brachiocephalic vein and the angle between the brachiocephalic vein and superior vena cava). Thus, the stiffening cannula should be guided with the guidewire and sheath under fluoroscopy when it passes through the mediastinal veins.

There are some limitations in our research. First, the middle hepatic vein with left portal vein puncture was preferred for TIPS creation, which is not the standard firstline approach (right hepatic vein to right portal vein) and thus could explain the abnormally high rates of hemoperitoneum. In addition, six different operators performed the TIPS procedures, which could bias group comparisons.
The left internal jugular vein could be used as primary access for TIPS creation in patients with a small liver and short vertical puncture distance.

Supplementary Information The online version contains supplementary material available at https://doi.org/10.1007/s00270021-03023-9.

Acknowledgements We are grateful to David Waldman, Ph.D., MD, Department of Imaging Sciences, University of Rochester Medical Center, for manuscript editing and review. This study was funded by the National Natural Science Foundation of China (Grant No. 81571780), the Science and Technology Planning Project of Guangdong Province (CN) (Grant No. 2017B020210004), and the Medical Science and Technology Foundation of Guangdong Province (A2019122).

Author contribution Conceptualization: FG, FZ. Data curation: ZQ, MZ, GW, WJ. Formal analysis: HQ, FG. Funding acquisition: FG, FZ, GW. Investigation: WZ, HY. Methodology: ZQ, WZ, HQ. Project administration: FG, JX. Resources: FG, FZ. Software: ZQ, GW. Supervision: HY, JX. Validation: FZ. Visualization: HQ. Writingoriginal draft: ZQ, WZ. Writing-review \& editing: HY, FZ, HQ, JX, FG. 
Funding National Natural Science Foundation of China, 81571780, Fei Gao, Science and Technology Planning Project of Guangdong Province, 2017B020210004, Fujun Zhang,Medical Science and Technology Foundation of Guangdong Province, A2019122, Guobao Wang.

\section{Declarations}

Conflict of interest All other authors declared that they do not have anything to disclose regarding funding or conflict of interest with respect to this manuscript.

Ethical Approval This study was performed according to the Declaration of Helsinki (2013) of the World Medical Association. It was approved by the Institutional Review Board of Sun Yat-sen University Cancer Center, and the informed consent of patients was exempted (B2020-265-01).

Open Access This article is licensed under a Creative Commons Attribution 4.0 International License, which permits use, sharing, adaptation, distribution and reproduction in any medium or format, as long as you give appropriate credit to the original author(s) and the source, provide a link to the Creative Commons licence, and indicate if changes were made. The images or other third party material in this article are included in the article's Creative Commons licence, unless indicated otherwise in a credit line to the material. If material is not included in the article's Creative Commons licence and your intended use is not permitted by statutory regulation or exceeds the permitted use, you will need to obtain permission directly from the copyright holder. To view a copy of this licence, visit http://creativecommons. org/licenses/by/4.0/.

\section{References}

1. Nicoara-Farcau O, Han G, Rudler M, Angrisani D, Monescillo A, Torres F, et al. Effects of Early Placement of Transjugular Portosystemic Shunts in Patients With High-Risk Acute Variceal
Bleeding: a Meta-analysis of Individual Patient Data. Gastroenterology 2021; 160(1):193-205 e110.

2. Tripathi D, Stanley AJ, Hayes PC, Travis S, Armstrong MJ, Tsochatzis EA, et al. Transjugular intrahepatic portosystemic stent-shunt in the management of portal hypertension. Gut. 2020;69(7):1173-92.

3. European Association for the Study of the Liver. Electronic address eee, European Association for the Study of the L. EASL Clinical Practice Guidelines for the management of patients with decompensated cirrhosis. J Hepatol 2018; 69(2):406-60.

4. Garcia-Tsao G, Abraldes JG, Berzigotti A, Bosch J. Portal hypertensive bleeding in cirrhosis: Risk stratification, diagnosis, and management: 2016 practice guidance by the American Association for the study of liver diseases. Hepatology. 2017;65(1):310-35.

5. Lv Y, Yang Z, Liu L, Li K, He C, Wang Z, et al. Early TIPS with covered stents versus standard treatment for acute variceal bleeding in patients with advanced cirrhosis: a randomised controlled trial. Lancet Gastroenterol Hepatol. 2019;4(8):587-98.

6. Dariushnia SR, Haskal ZJ, Midia M, Martin LG, Walker TG, Kalva SP, et al. Quality improvement guidelines for transjugular intrahepatic portosystemic shunts. J Vasc Interv Radiol. 2016;27(1):1-7.

7. Schuppan D, Afdhal NH. Liver cirrhosis. Lancet. 2008;371(9615):838-51.

8. Vasconcelos-Filho JM, Pereira AH, Pitta GBB, Leitao-Batista L, Castro AA, Souza-Leao AR, et al. Measurements between the hepatic veins and portal venous system, in human cirrhotic liver: a cast study. Surg Radiol Anat. 2018;40(4):395-400.

9. Buckley JG, Bocchini TP, Zuckerman DA. Transjugular intrahepatic portosystemic shunt: the left internal jugular vein approach. AJR Am J Roentgenol. 1993;160(2):420-1.

10. Hausegger KA, Tauss J, Karaic K, Klein GE, Uggowitzer M. Use of the left internal jugular vein approach for transjugular portosystemic shunt. AJR Am J Roentgenol. 1998;171(6):1637-9.

Publisher's Note Springer Nature remains neutral with regard to jurisdictional claims in published maps and institutional affiliations. 